\title{
PENGAMANAN NESTED VIRTUALIZATION SERVER UNTUK E-LEARNING MOODLE PADA PROXMOX VE MENGGUNAKAN METODE HIGH AVAILABILITY
}

\author{
${ }^{1}$ Asep Sofyan Wahyudin \\ ${ }^{2}$ Muhamad Abdul Aziz \\ ${ }^{3}$ Eryan Ahmad Firdaus \\ ${ }^{4}$ Kanggep Andrijana Kusuma
1,2,3,4 Program Studi Pascasarjana, Magister Sistem Informasi, Sekolah Tinggi
Manajemen Informatika Dan Komputer Likmi
Email: ${ }^{1}$ sofyan.wahyudin@gmail.com, ${ }^{2}$ ziz.boxer@gmail.com,
${ }^{3}$ eryan.ahmad@gmail.com, ${ }^{4}$ kanggepandriana@gmail.com

\begin{abstract}
ABSTRAK
Perkembangan teknologi komputasi saat ini luar biasa sangan pesat, tak sedikit sebuah server yang dulunya hanya dimanfaatkan untuk menangani satu layanan saja, kini hal itu sudah di anggap sebagai pemborosan resource, salah satu penyebabnya adalah perkembangan metode virtualisasi yang di anggap dapat mengoptimalkan sebuah server untuk menangani lebih banyak layanan dengan cara membuat beberapa mesin virtual dalam satu mesin real untuk memaksimalkan kemampuan server, lalu apakan dalam sebuah mesin virtual dapat menjalakan mesin virtual lagi, amankah bila digunakan untuk menangani layanan sistem informasi secara optimal.
\end{abstract}

Kata Kunci-Virtualisasi Bersarang, E-Learning, High Availability.

\begin{abstract}
The development of computing technology is currently very fast, not a few servers that were previously only used to handle one service, now it is considered a waste of resources, one of the causes is the development of virtualization methods which are considered to optimize servers for more services by creating several virtual machines in to one real machine to maximize server capabilities, so in a virtual machine can it run the virtual machine again, is it safe to using it for optimal information system services.
\end{abstract}

Keyword- Nested Virtualization, E-Learning, High Availability.

\section{PENDAHULUAN}

Tren komputer saat ini semakin matang, dengan harga semakin murah, yang memungkinkan pengguna rumahan dan bisnis memiliki komputer multi-core dan multithread seperti seri dari Intel Core dan seri AMD Ryzen. Faktanya, tidak semua aplikasi 
saat ini, terutama yang bukan diperuntukan untuk proses render video dan aplikasi game, dapat memanfaatkan prosesor multi-core ini dengan sebaik-baiknya [1].

Menurut pengamatan Tony Iams, seorang analis senior di D.H. Brown Associates Inc, NY, sebagian besar server hanya menggunakan 15\% hingga 20\% dari kapasitas sebenarnya. Tentu saja, jumlah ini jauh dari ideal [2]. Virtualisasi adalah salah satu solusi memaksimalkan kemampuan sebuah PC untuk dijadikan sebuah server

Untuk meningkatkan kualitas server diperlukan solusi dimana ketika sebuah node mengalami kendala maka mesin virtual dapat dipindahkan ke node lain untuk meminimalisir penurunan layanan yang diakses oleh klien. Mayoritas praktisi IT tidak akan menyarankan penggunaan server virtual secara nested, karena diragukan kemampuannya akan berjalan secara optimal, namun tidak ada salahnya kita mencoba mencari solusi memanfaatkan teknologi ini untu kebutuhan penyedia layanan sistem informasi dan mencari solusi tengah karena makin kesini software virtualisasi terus dikembangkan dan kinerjanya makin optima

Salah satu contoh software virtualisasi yaitu VMware Workstation yang berfungsi sebagai perangkat lunak mesin virtual untuk arsitektur komputer x86 dan x86-64 dari VMware (bagian dari EMC Corporation). Perangkat lunak ini digunakan untuk membuat beberapa komputer virtual x86 dan x86-64 dan menggunakannya secara bersamaan dengan sistem operasi yang digunakan. Setiap mesin virtual dapat menjalankan sistem operasi yang dipilih, seperti varian Windows, Linux, BSD, dll. Sederhananya, VMware Workstation dapat menggunakan mesin fisik untuk menjalankan beberapa sistem operasi pada waktu yang bersamaan.

Mesin virtual yang handal lainnya adalah Proxmox VE, dimana server open source untuk virtualisasi ini sudah terintegrasi dengan hypervisor KVM dan LXC. Dengan antarmuka pengguna berbasis web terintegrasi, sehingga kita dapat dengan mudah mengelola VM dan kontainer (LXC).

Terminologi Nested Virtualization sendiri merujuk pada mode virtualisasi yang beroperasi di dalam lingkungan yang telah tervirtualisasi. Dengan kata lain, nested virtualization merupakan kemampuan untuk menjalankan hypervisor di dalam Virtual Machine (VM) dimana VM tersebut juga beroperasi di atas hypervisor. 
Fitur utama yang dapat dimanfaatkan dari Proxmox VE adalah High Availability server yang berguna untuk memprediksi kegagalan atau kerusakan peralatan pada komputer server yang dapat mengganggu kinerja sistem jaringan.

Tidak semua hypervisor dan sistem operasi mendukung virtualisasi bersarang. Hypervisor yang mendukung virtualisasi bertingkat mencakup hypervisor KVM dan VMware ESXi. ESXi bersarang juga mendukung hypervisor tamu Hyper-V, Xen, dan KVM pada ESXi 6.0.

Virtualisasi bersarang dapat dimanfaatkan untuk tujuan pengembangan, pengujian dan pelatihan virtualisasi [3].

\section{METODE PENELITIAN}

Ujicoba penelitian sengaja dilakukan menggunakan hardware yang secara kemampuan bisa dikatakan sangat kurang ideal dengan tujuan untuk mencari jawaban seberapa jauh kemampuan mesin virtualisasi dapat bekerja secara nested, kegiatan penelitian di lakukan pada Lab. jaringan di SMK Pasundan 1 Banjaran dengan memanfaatkan server yang sedang berjalan dengan bantuan mesin virtualisasi VMWare Workstation yang nantinya akan di kombinasikan dengan Proxmox VE untuk menjalankan LMS e-learning Moodle pada Container LXC, dimana untuk mendapatkan hasil pengujian dilakukan dengan melakukan benchmarking pada moodle, pemantauan trafik jaringan dan aktifitas media storange.

Pada simulasi ini dua buah Proxmox VE diajalankan secara nested di dalam VMware yang berjalan diatas Windows 10, sekemanya seperti gambar di bawah ini.

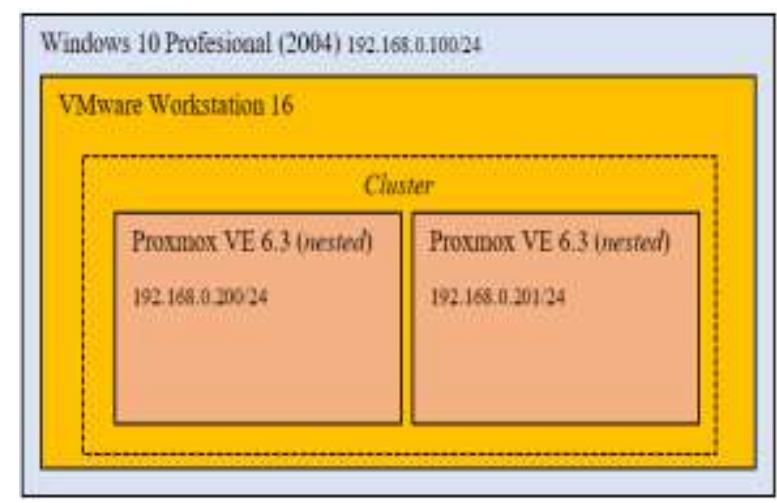

Gambar 1

Contoh skema penerapan Nested Virtualization 


\section{HASIL DAN PEMBAHASAN}

\subsection{Penerapan Nested Virtualisasi dan Clustering Server}

Spesifikasi hardware yang digunakan yaitu Prosesor: Intel Core i5 4460 Processor (4C/4T, 6MB cache, 3.40GHz Boost), Memori RAM: 16GB DDR3. Dengan penyimpanan: 256GB SSD dan 500GB HDD.

Dua buah Proxmox VE dijalankan dengan memanfaatkan fitur VT-x atau AMD-V yang mana keduanya adalah fitur yang mengijinkan sebuah prosessor mengekspos semua kemampuannya prosessor fisik ke mesin virtual yang sedang berjalan.

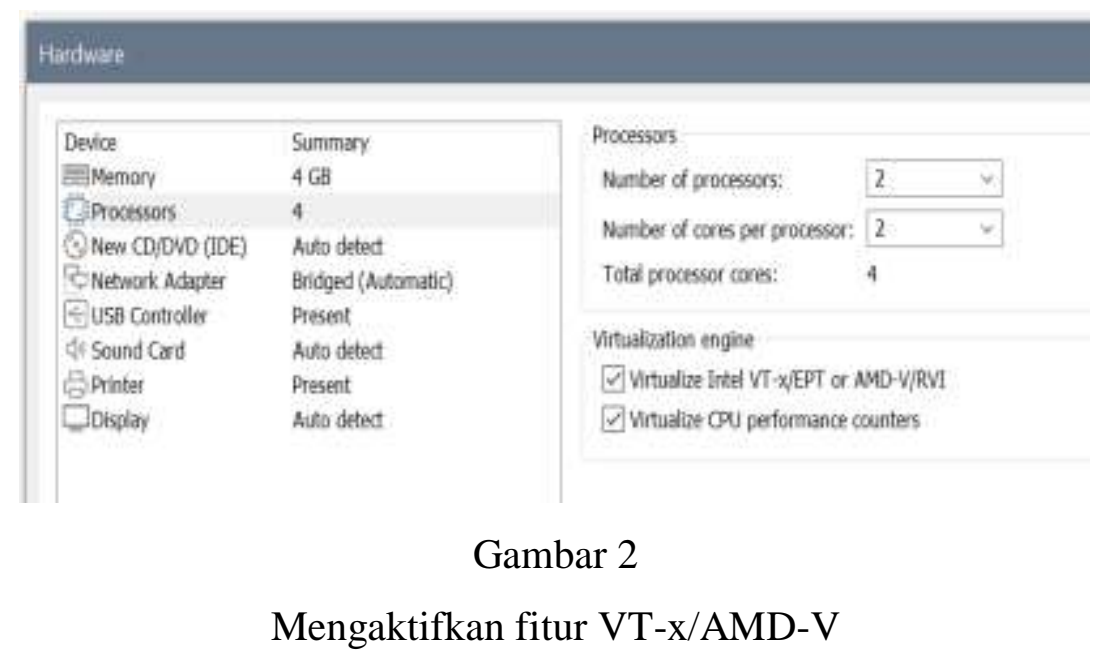

Setelah kita membangun dua buah server Proxmox VE secara nested pada VMware, langkah selanjutnya adalah menghubungkan kedua server virtualisasi itu secara clustering, untuk mengaktifkannya kita dapat masuk di menu Datacenter $\rightarrow$ Cluster

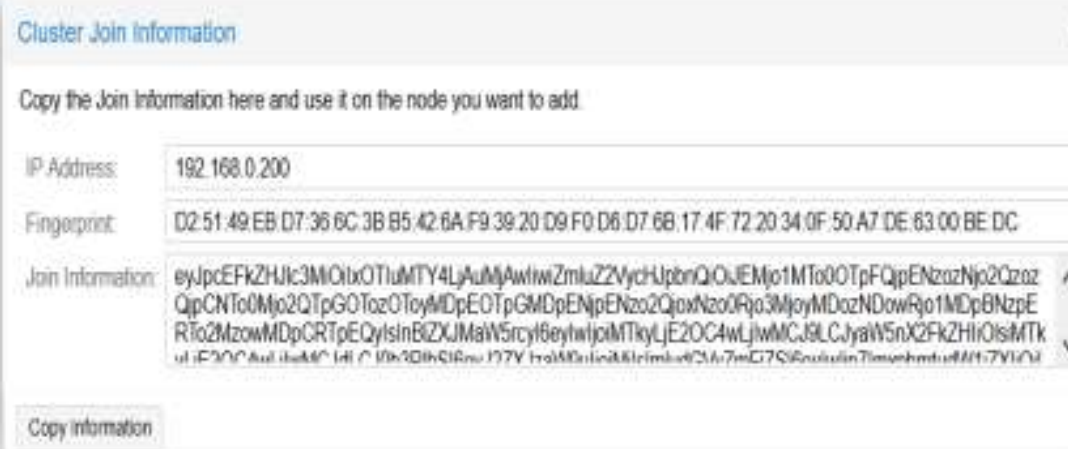

Gambar 3

Membuat cluster pada server Proxmox VE 


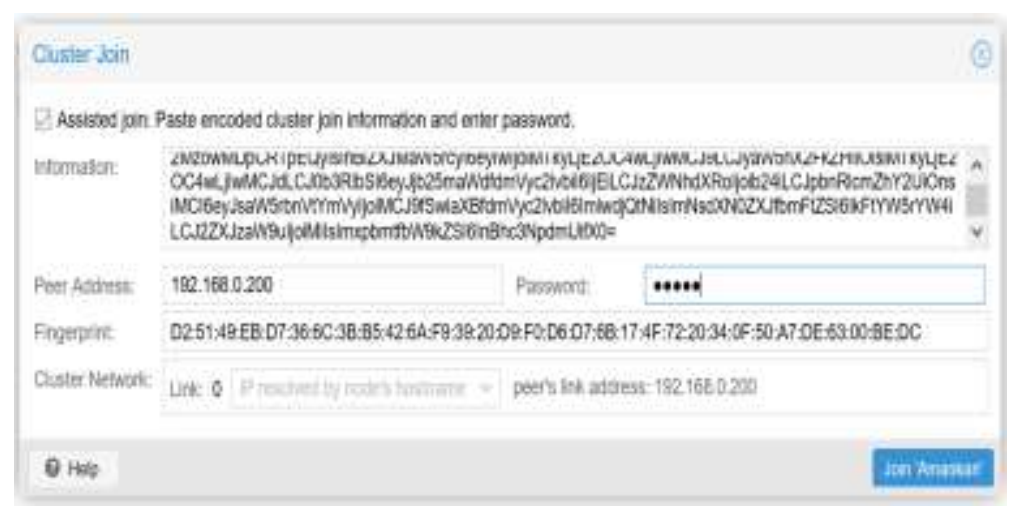

\section{Gambar 4}

Melakukan join dua buah Node server Proxmox VE

\subsection{Mengaktifkan High Availability}

a. Ceph adalah penyimpanan objek dan sistem file terdistribusi yang dirancang untuk memberikan kinerja, keandalan, dan skalabilitas yang sangat baik, untuk melakukan failover kita perlu memasang ceph pada tiap node

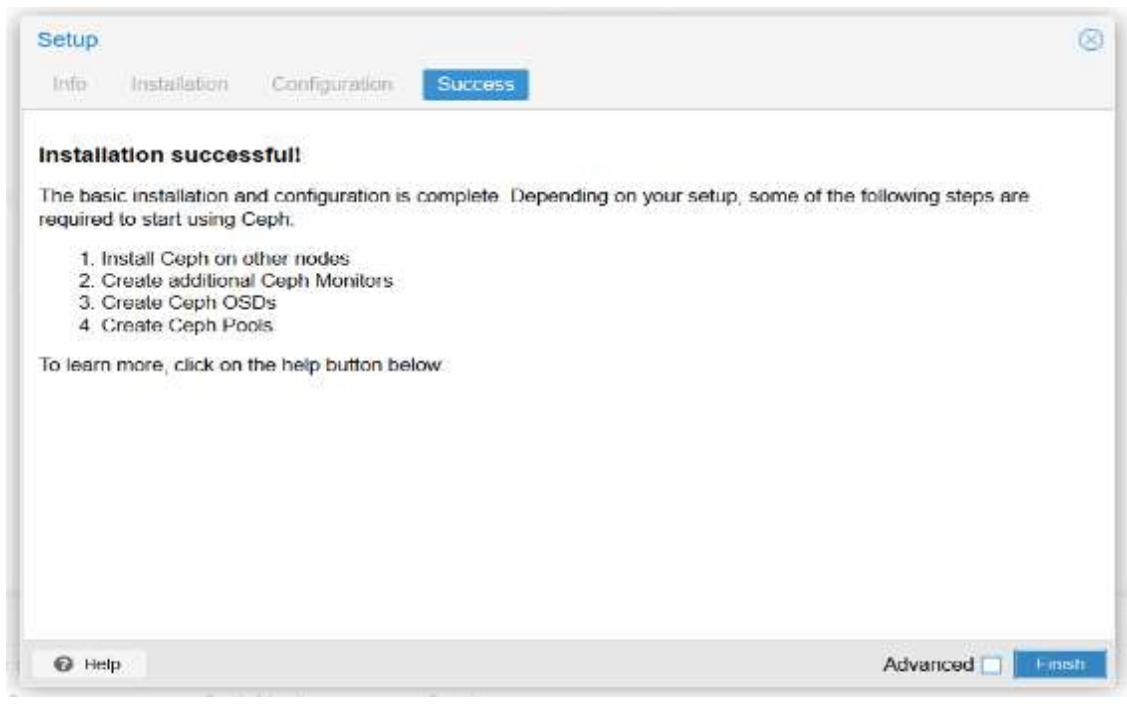

\section{Gambar 5}

Melakukan instalasi dan konfigurasi pada tiap node Proxmox VE

b. Membuat OSD (Object Storage Daemon) pada masing masing node yang berfungsi untuk menyimpan virtual disk vm dan container. Untuk define awal OSD harus hatihati karena akan menghapus semua data pada disk yang didaftarkan sebagai OSD. 
Asep, Sofyan Wahyudin, Muhamad Abdul Azis, Eryan Ahmad Firdaus, Kanggep Andrijana Kusuma Vol 6 No 1

c. Membuat pool penyimpanan untuk menempatkan Virtual Machine atau Container LXC

d. Jika tahap di atas telah di lakukan maka kita sudah siap memasang sebuah Container

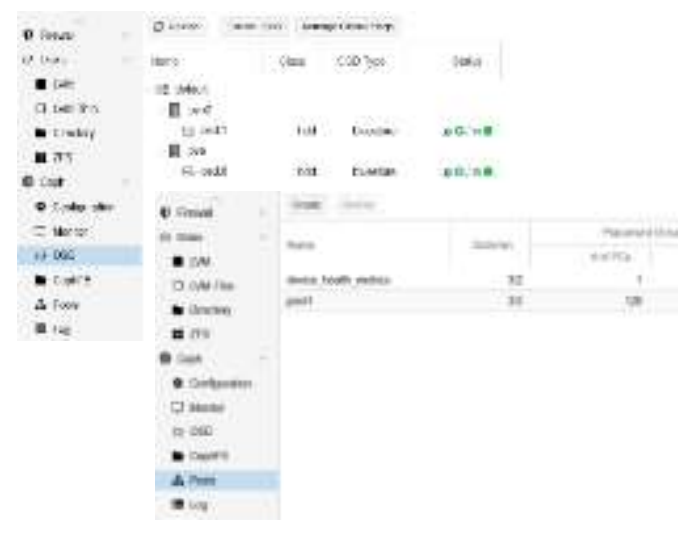

Gambar 6

Membuat OSD pada tiap node dan mengabungkan menjadi sebuah pool penyimpanan

e. LXC yang dikelola oleh HA (High Availability)

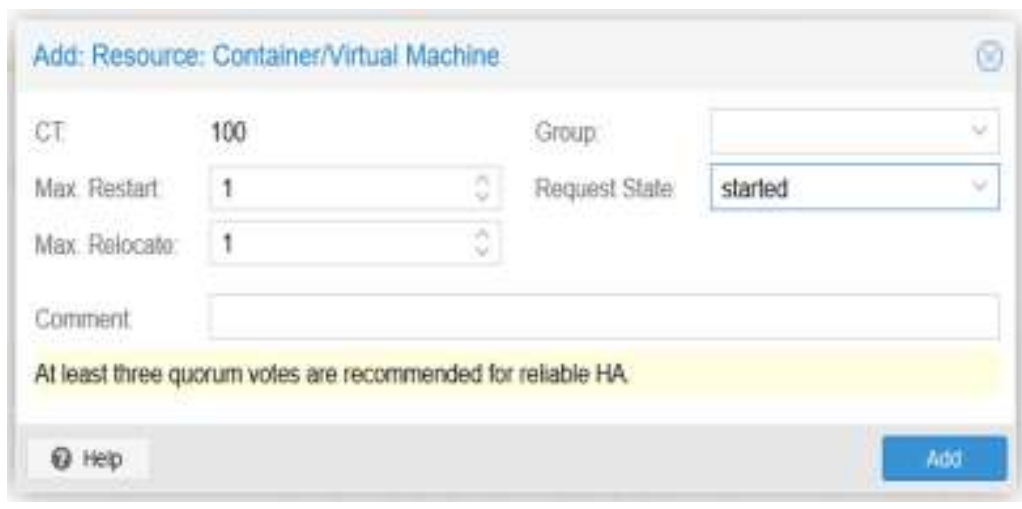

Gambar 7

Mengaktifkan mode HA untuk LXC yang akan dibagun sebagai server

\subsection{Instalasi Web Server dan Database Server pada $L X C$}

Linux Container (LXC) adalah virtualisasi sistem operasi yang memungkinkan kita menjalankan beberapa sistem Linux pada sistem komputer pada waktu yang bersamaan. Tentu saja, platform ini hanya berlaku untuk Linux. Kelebihan menggunakan LXC 
dibandingkan Virtual Machine adalah karena ketika kita menggunakan Container LXC, performanya tidak jauh beda ketika kita menjalankan pada mesin secara langsung.

Tahapannya sebagai berikut:

a. Update repository dan upgrade LXC

\# apt update

\# apt upgrade

b. Install Web server, Database server dan PHP beserta extension yang akan dibutuhkan \# apt install apache2 mysql-client mysql-server php libapache2-mod-php \# apt install graphviz aspell ghostscript clamav php7.4-pspell php7.4-curl php7.4-gd php7.4-intl php7.4-mysql php7.4-xml php7.4-xmlrpc php7.4-ldap php7.4-zip php7.4soap php7.4-mbstring

c. Sekarang kita perlu membuat Database menggunakan MySQL Server untuk Moodle dan membuat user baru

\# mysql

mysql> CREATE DATABASE moodle DEFAULT CHARACTER SET utf8mb4 COLLATE utf8mb4_unicode_ci;

mysql> CREATE USER 'admin' @'\%' IDENTIFIED BY 'pass';

mysql> GRANT ALL PRIVILEGES ON *.* TO 'admin'@'\%' WITH GRANT OPTION;

mysql> quit;

d. Membuat folder untuk menyimpan data LMS Moodle \# chmod -R 777 /var/www/html/moodle \# chmod -R 0755 /var/www/html/moodle

e. Download LMS Moodle dan masukan ke dalam folder /var/www/html/ untuk tahap ini banyak cara yang bisa di lakukan, misalnya dengan membuka akses ssh supaya dapat di akses oleh root menggunakan aplikasi WinSCP atau FileZilla.

Setelah berhasil melakukan instalasi, untuk menguji performa Web Server dan Database yang kita bangun, di sini saya mengunakan plugin Moodle Benchmark yang di instal secara manual dari https://moodle.org/plugins/report_benchmark, berikut adalah hasilnya: 


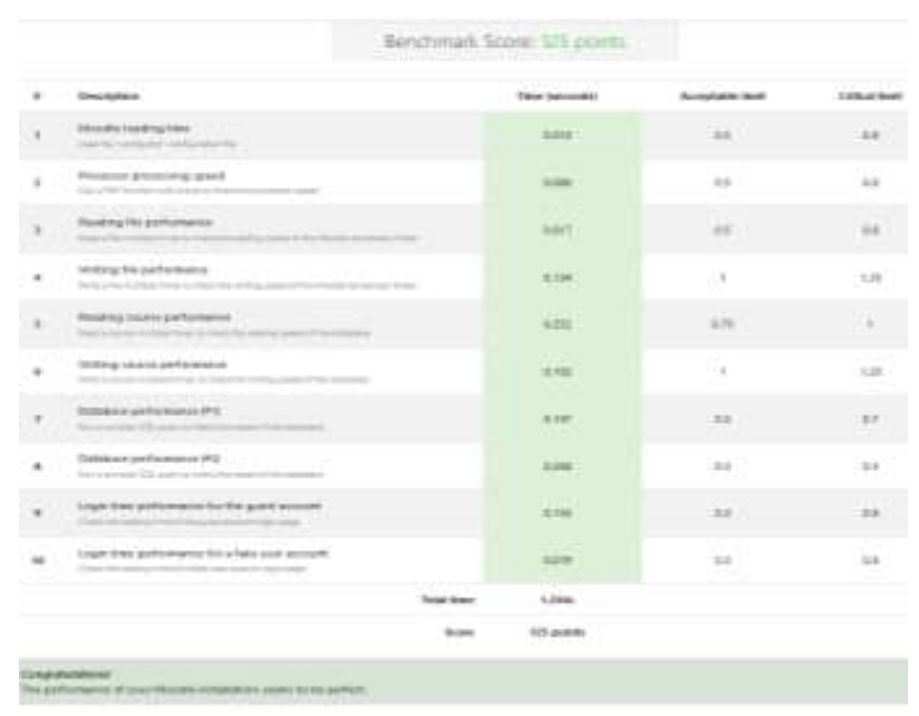

Gambar 8

Hasil benchmark pada LMS Moodle untuk melihat performa server pada sebuah Nested Virtualisasi

\section{KESIMPULAN DAN IMPLIKASI}

\subsection{Kesimpulan}

Pengguanaan Nested Virtualization dapat menjadi solusi ketika kita mengiginkan server yang fleksible dalam melakukan Availability dan Scalability dengan penurunan performa yang hanya berkisar di bawah angka 5-10\% dibandingkan ketika menjalankan langsug pada server fisik, namun ada beberapa hasil yang harus menjadi pertimbangan ketika melakukan metode ini, diantaranya:

a. penerapan teknik High Availability pada server yang di konfigurasi secara Nested cukup membebani kerja media penyimpanan ketika melaukan singkronisasi untuk mengabungkan dua buah storange menjadi satu

b. trafik jaringan terpantau cukup tinggi, dikarenakan komunikasi jaringan mengunakan bantuan emulasi secara software.

\subsection{Implikasi}

Ujicoba sengaja dilakukan pada kondisi yang sangan tidak ideal supaya dapat mengukur sejauh kemampuan sebuah nested virtualisasi dapat bekerja, untuk kedepannya ujicoba dapat dikakukang menggunakan hardware yang lebih layak minimal menggunakan dua buah server dalam satu jaringan dengan menggunakan SSD lebih besar dan Interface Gigabit Ethernet supaya dapat bekerja lebih optimal. 


\section{DAFTAR PUSTAKA}

[1]. Novan A., Widyawan, Sujoko S. 2012, Pengembangan Virtual Appliance Server Dengan Metode Virtualisasi, JNTETI, vol. 1, hal 18-23।

[2]. D.H. Brown Associates, Inc. 2001. VMware: Tool for Server Consolidation http://www.vmware.com/pdf/vmware-dhbrown.pdf, diakses tgl 6 Desember 2020

[3].C. Zonyfar, S. Sihabudin, and A. Khusaeri, "Peningkatan Kemampuan Siswa dalam Memanfaatkan Sumber Belajar di Internet Melalui Sosialisasi Edukasi Internet Cerdas, Sehat, dan Aman”, tribhakti, vol. 1, no. 1, pp. 17-20, Dec. 2019.

[4].Forrest Stroud, Nested Virtualization, https://www.webopedia.com/definitions/nested-virtualization/, diakses tanggal 6 Februari 2020

[5].KVM \& OpenVZ virtualization based IaaS open source cloud virtualization platforms: OpenNode, Proxmox VE, http://ieeexplore.ieee.org/document/6339540/, diakses tanggal 6 Desember 2020

[6].Linda A., Ucuk D., Novi D., 2018, Clustering Server Cloud Computing High Availability, (JOINTECS) Journal of Information Technology and Computer Science Vol. 3, hal. 23-28

[7].Proxmox Virtual Environment, https://www.proxmox.com/en/proxmox-ve, diakses tgl 18 Desember 2020

[8].S. . and C. Zonyfar, "Social Media Marketing and Brand Awareness for Millennial Generation”, J Arch.Egyptol, vol. 17, no. 1, pp. 131-140, Nov. 2020.

[9].Zonyfar, C., Baihaqi, K. A., \& Pertiwi, A. B. (2020). Pixel value differencing and modulus function method for embedded message in digital images. International Journal of Psychosocial Rehabilitation, 24(7), 3379-3385.

[10]. Zonyfar, C., Maharina, Zayn, M. \& Barack, E., 2020. Student Enrollment: Data Mining Using Naïve Bayes Algorithm. Journal of Advanced Research in Dynamical and Control Systems, pp. 1077-1083. 